\title{
Onkologie
}

\section{Liquid Biopsy}

\section{Prognose und Rückfallerkennung bei Kinderkrebs präzisiert}

Das Team Tumorbiologie der St. Anna Kinderkrebsforschung unter der Leitung von Univ. Doz. Dr. Peter Ambros gemeinsam mitDr. Inge Ambros, aktuell geleitet von Dr. Sabine Taschner-Mandl, hat es sich zum Ziel gesetzt, gemeinsam mit Forschungspartnern aus der Charité Berlin, dem Institut Curie in Paris, der Universität Gent und dem deutschen Krebsforschungszentrum in Heidelberg, den genetischen Hintergrund von Neuroblastomen mit modernsten Methoden zu untersuchen, um dessen Auswirkungen auf die klinische Prognose zu erforschen und eine verlässliche Grundlage für liquid biopsy Untersuchungen zu erhalten.

\section{Frühere Rückfallerkennung durch Flüssigbiopsie}

Das Forscherteam untersuchte die prognostische Relevanz der sog. „Flüssigbiopsie“. Dieses Verfahren basiert auf der Tatsache, dass aus Tumorzellen freigesetzte DNA meist auch im Blut nachzuweisen ist, was deren Analyse mit hochsensitiven Methoden erlaubt. Im
Gegensatz zur Tumorbiopsie ist die Entnahme von Blutproben als nicht bzw. kaum invasiv einzustufen und kann daher oftmals im Verlauf der Erkrankung im Rahmen von routinemäßig durchgeführten Blutuntersuchungen durchgeführt werden. Um dies zu ermöglichen, hat das Forscherteam die Methoden für Genomanalysen adaptiert. Dies ist speziell bei Säuglingen und Kleinkindern relevant, da jede zusätzliche Blutabnahme vermieden werden sollte.

\section{Pilotstudie}

Ziel dieser Studie war die Klärung der Frage, ob dieses Verfahren bei Neuroblastom-Patienten und -Patientinnen einen zusätzlichen klinischen Vorteil bringt. In einer Pilotstudie konnte nun gezeigt werden, dass der Nachweis von Tumor DNA aus dem peripheren Blut von Kindern mit Neuroblastomen neben der seit Jahren verwendeten ultra-sensitiven Knochenmarkanalyse eine sehr sensitive zusätzliche Methode darstellt, um ein engmaschiges Monitoring durchführen zu können. Wir

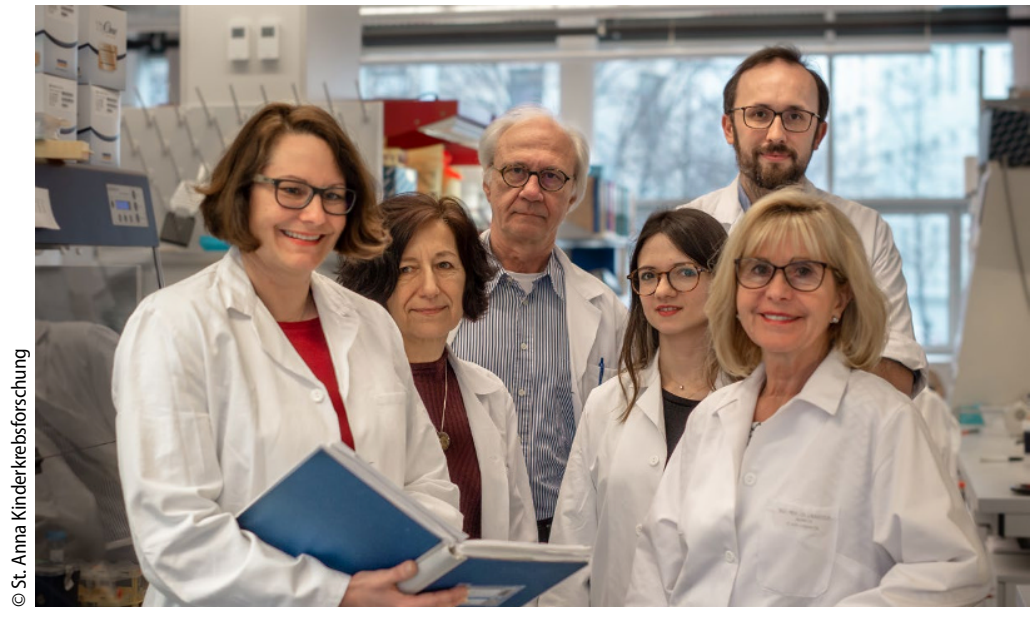

$\Delta$ Team Tumorbiologie und Forschungspartner im Projekt ONTHETRRAC; v. I. n. r.: Sabine Taschner-Mandl, Inge Ambros, Peter Ambros, Polyxeni Bozatzi, Fikret Rifatbegovic, Ruth Ladenstein konnten mit diesem Verfahren auch nachweisen, dass ein Rezidiv schon bei geringer Tumorlast und noch vor seiner klinischen Manifestation nachweisbar ist. Diese Daten, die an bisher $19 \mathrm{~Pa}$ tienten gewonnen werden konnten, sind äußerst vielversprechend, müssen aber noch in einer internationalen Studie validiert werden.

"Von nun an wird die Anwendung modernster Flüssigbiopsie-Techniken und damit der Nachweis selbst geringer Mengen von Tumor-DNA im Blut einen wichtigen Pfeiler für den Krankheitsverlauf und die prä-klinische Rückfallserkennung bei Neuroblastom Patienten und Patientinnen darstellen", so der Studienleiter Univ.-Doz. Dr. Peter Ambros.

\section{Förderung}

Das Projekt "Overcoming Neuroblastoma Tumour HETerogeneity, Resistance and RecurrAnCe" (ONTHETRRAC) wurde mittels Förderung durch den Österreichischen Wissenschaftsfonds (FWF, Internationales Programm ERANET für Krebsforschung, TRANSCAN), sowie durch die nationalen Fördergeber der Kooperationspartner finanziert und mit Ende Oktober 2019 erfolgreich abgeschlossen.

\section{Weitere Informationen:}

www.ccri.at

Hinweis des Verlags. Der Verlag bleibt in Hinblick auf geografische Zuordnungen und Gebietsbezeichnungen in veröffentlichten Karten und Institutsadressen neutral.

Paediatr. Paedolog. 2020 · 55:207 https://doi.org/10.1007/s00608020-00822-0

๑) Springer-Verlag GmbH Austria, ein Teil von Springer Nature 2020
Quelle: Pressemeldung St. Anna Kinderspital, Wien, 13.05.2020 